\title{
SUPPLEMENT
}

\author{
Selim Serter ${ }^{1}$ \\ Erkan Sabin ${ }^{1}$ \\ Utku Mabir Yildirim ${ }^{1}$ \\ Murat Arslan' \\ Ayhan Karakose ${ }^{2}$
}

${ }^{1}$ Department of Radiology, Faculty of Medicine, Izmir University, Izmir, Turkey ${ }^{2}$ Department of Urology, Faculty of Medicine, Izmir University, Izmir, Turkey

\section{Unenhanced computed tomography findings of renal papillae in patients with a ureteral stone}

\begin{abstract}
Purpose: In some patients with a ureteral stone without uretero-hydronephrosis, it is difficult to determine the location of the stone. The objective of the present study was to investigate the changes in renal papillae using unenhanced computerized tomography $(\mathrm{uCT})$ and determine the side of calculi using the renal papillary findings in patients with a ureteral stone.

Methods: uCT data from 81 patients were retrospectively reviewed for this study. The inclusion criteria were unilateral ureteral calculi, no renal calculi and no hydronephrosis. For each patient, three measurements of CT attenuation of $0.05 \mathrm{~cm}^{2}$ area were made in the tip of the interested renal papillae, both stone side and non-stone side. Student's t test was used for statistical analysis.

Results: Forty-one right-sided and 40 left- sided isolated unilateral ureteral calculi patients were evaluated by uCT exam. The average attenuations of the tip of the papillae in stone side and non-stone side were 34.1 Hounsfield units (HU) and $30.6 \mathrm{HU}$, respectively. There was a statistically significant difference between stone and non-stone sides $(\mathrm{p}<$ $0.05)$.

Conclusion: During routine practical uCT applications, it can be difficult to distinguish phleboliths, ureteral stone or the existence of non-opaque ureteral stone, so papillae density measurements can be a practical method to identify the existence of ureter stone and its location (side).
\end{abstract}

\section{Correspondence to:}

Selim Serter, M.D.

Izmir University, School of Medicine, Department of Radiology

Yeni Girne Bulvarı, 1825 Sk. No: 12, Karsiyaka

Izmir, Turkey

E-mail: serterselim@gmail.com 
Unenhanced computed tomography ( $\mathrm{uCT}$ ) of the urinary tract has replaced intravenous urography as the imaging method of choice for a patient presenting with suspected renal colic $[1,2]$. The procedure is quick and no contrast agent is required. In the last decade, $\mathrm{uCT}$ is considered as a gold standard in the diagnosis of urinary calculi with high sensitivity and specificity of over $90 \%$ [3].

The etiopathogenesis of the stone disease remains unclear. One of the most popular theories of calcium stone formation involves the appearance of calcified plaques over the renal papillae that could serve as a nucleus for stone formation [4]. There is substantial evidence supporting this concept [5-11]. Calcification similar to Randall's plaques and suburothelial calcium deposits on the papillary tip have been described in calcium oxalate stone formers, in patients with enteric hyperoxaluria and in brushite stone formers [12]. Histopathology of renal papillae biopsies shows the presence of calcium oxalate and phosphate deposits in the majority of stone formers $[5,11]$. In many patients, calculi have been found growing attached to the papillae to Randall's plaques [6, 7]. Also the proportion of papillary surface covered by Randall's plaques correlates with the number of stones formed [8]. Additionally, in the same patients, stones found loose in the urinary system show evidence that they once were attached to a plaque [9]. For these reasons, papillary tip calcification is thought to be the origin for stone formation $[6,12,13]$.

Although $\mathrm{uCT}$ is considered the gold standard of urinary calculi, there is scarce information regarding CT images of renal papillae of stone-forming patients. It has been demonstrated, in two retrospective studies, that in patients with active stone disease, the area of the tip of the renal papillae appeared more hyperdense on $\mathrm{uCT}$ then in control patients $[14,15]$. Recent studies showed that stone forming patients exhibited higher papillary density even before calculi development $[13,16]$. Obviously the density of papillae was not as high as visible renal calculi because of the microscopic nature of such soft tissue calcification compared with compact stones [15].

Our hypothesis was that papillary density, measured using $\mathrm{uCT}$, might be able to predict the existence of ureteral stone and its location (side), and we aimed to demonstrate the differences in the density of the tip of renal papillae in patients with unilateral ureteral stone.

\section{Materials and Methods}

A retrospective review of our database for all patients with ureteral stones was performed. We reviewed the data of 81 patients referred for uCT examination between January 2013 -
December 2014. Forty-one left side and 40 right side isolated ureteral stone patient were included in the study according to the inclusion criteria: presenting with acute pain suggestive of renal colic; and, unilateral ureteral stone detected by uCT. The exclusion criteria were ureteralstone size $<2 \mathrm{~mm}$ or $>8 \mathrm{~mm}$, renal stone, metal artifacts at the level of stone, hydronephrosis, recent ureteral instrumentation, previous renal-ureteral surgery, external trauma and compression.

uCT was performed using Toshiba Alexion (Ottawara, Japan) 16 slice multidetector CT equipment. Low dose uCT protocol for urinary tract was used with the acquisition parameters of $120 \mathrm{kV}, 90-110 \mathrm{~mA}$, standard filter (filter Sure IQ, body standard axial filter), SURE exposure 3D mA modulation, supine position. The field of view was $430 \mathrm{~mm}$, $512 \times 512$ matrix gives in a plane pixel size of approximately 1 $\mathrm{mm}$. The CT images were retrospectively reviewed using a Novarad ${ }^{\circ}$ NovaPACS (Picture Archiving and Computing System) 3D workstation (UT, USA). The images interpreted with dedicated CT Workstation (Vitrea Toshiba Medical Systems Ottawara Japan version XX) with two eizo force R22 color LCD monitors. (Eizo nanao corp., Ischikawa, Japan). Two experienced radiologist interpreted the images and a consensus was obtained that each set of measurements were done correctly.

Renal papillary density was measured (in Hounsfield units, $\mathrm{HU}$ ) by placing regions of interest (ROIs) with a mean size of $0.05 \mathrm{~cm}^{2}$ over the very tip of the papilla both ureteral stone side and stone-free side of kidneys. The images were magnified to prevent contamination of the ROI with fat within the renal sinus. Each kidney was divided into three parts corresponding to the three calyceal groups; in each one the attenuation of the renal papillae was recorded. Thus, a total of six measurements for each patient were recorded, three in each kidney, using the uCT images. In every kidney, one papilla from each calyceal group was measured, choosing the easiest to identify (Figures 1 and 2). At the workstation, the easiest plane was chosen in multiplanar reconstruction algorithm and papillae density measured. Sometimes oblique-semi oblique planes were used according to papilla orientation. After the measurements, the mean attenuation of these papillae was calculated for each kidney both stone side and stone free side.

Data analyses were performed by using SPSS (Statistical Package for Social Science version 16). Data were shown as mean \pm SD. Student-t test was used for comparison of groups. A p value $<0.05$ was considered as statistically significant. 


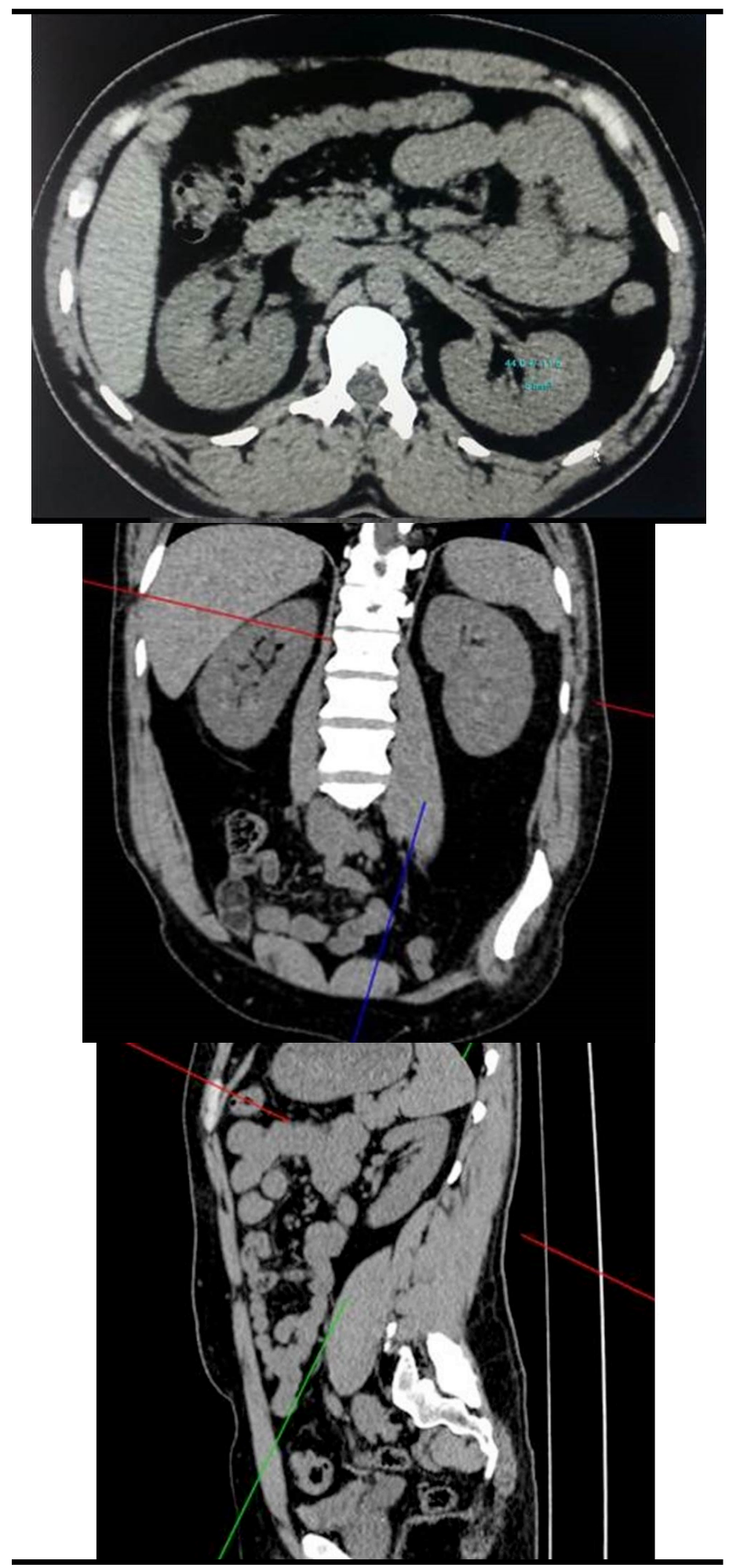

FIGURE 1. The multiplanary reconstruction images (MPR) include axial (a), coronal (b) and sagittal (c) images. The easiest plane was chosen in MPR algorithm to measure papillae density. Semioblique plane was chosen according to papilla orientation and papilla density was measured by ROI.

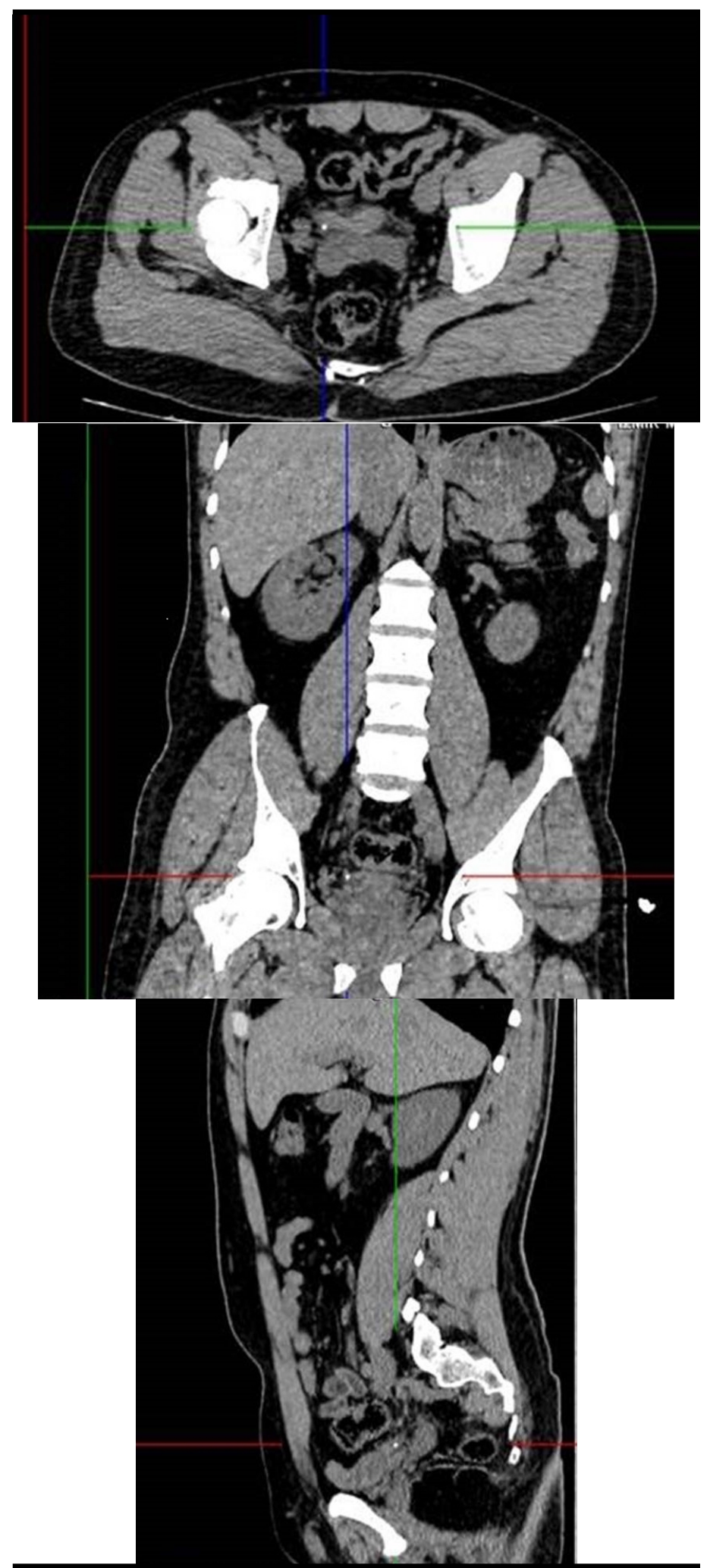

FIGURE 2. The MPR images include axial (a) coronal (b) and sagittal (c) display show unilaterally ureteral stone located distal part of the ureter without cause dilatation. 
TABLE 1. Papillary density of kidneys with or without ureteral stone

\begin{tabular}{l|c|c|c}
\hline Papillary density & $\begin{array}{c}\text { Stone-free side } \\
(\mathbf{n}=\mathbf{8 1}) \\
(\mathrm{R} / \mathrm{L}: \mathbf{4 0 / 4 1 )} \\
\text { mean } \pm \text { SD }\end{array}$ & $\begin{array}{c}\text { Stone side } \\
(\mathbf{n}=\mathbf{8 1}) \\
(\mathrm{R} / \mathrm{L}: \mathbf{4 1} / 40) \\
\text { mean } \pm \text { SD }\end{array}$ & $\mathrm{p}$ \\
\hline $\begin{array}{l}\text { Total renal apillary } \\
\text { attenuation }\end{array}$ & $34.1 \pm 6.1$ & $30.6 \pm 6.1$ & $<0.05$ \\
\hline Upper pole papillae & $32.8 \pm 7,2$ & $31.2 \pm 8,2$ & 148 \\
\hline Middle papillae & $34.8 \pm 7,5$ & $29.7 \pm 7,2$ & $<0.05$ \\
\hline Lower pole papillae & $34.7 \pm 8,4$ & $31.1 \pm 8,0$ & $<0.05$ \\
\hline
\end{tabular}

R: right, L: left

\section{Results}

uCT images of 81 patients ( 38 female and 43 male), each with single unilateral ureteral calculus, were reviewed retrospectively. The stones were on the left side in 41 patients $(50.6 \%)$ and on the right side in the remaining 40 patients ( $49.4 \%)$. The average age of the patients was found 40.0 years (range 20-68, SD 11.1). No patient received iodinated agents before the uCT.

Statistically significant differences were found in attenuation of the renal papillae between stone side and non-stone side. The average attenuation of the tip of the papilla was lower in stone side when compared to the stone-free side (34.1 HU versus $30.6 \mathrm{HU}, \mathrm{p}<0.05)$. Table 1 shows all measurements and mean values of both kidneys.

\section{Discussion}

Recently, different CT applications have been used in urogenital radiology practice [16-21]. Measurement of attenuation values in CT is already a routine procedure for the analysis of renal calculi and characterization of benign and malignant lesions of the kidney and urinary tract $[17,18]$. Dual source dual energy CT is a reliable imaging technique in the evaluation of complex cystic renal masses. The colour-coded iodine overlay technique is a useful tool for both excluding and identifying endocystic enhancement [22]. The ability of CT to discriminate between the attenuation values of various tissues has been helped comparative investigation of the various zones of kidneys. A steady interest in measuring the attenuation of renal papillae has continued for years [13-16].

In a recent study, the similar papillary attenuation values found in both kidneys suggested that the formation of Randall's plaques is a systemic process in patients with unilateral calculi [16]. Indeed, several previous reports have mentioned increased Hounsfield unit density of the renal papillae in patients with nephrolithiasis, irrespective of which side had the stone $[14,15]$. Conversely, in our study, the average density value of the renal papillae for the ureteral stone side was found to be lower than that of non-stone side. Actually, the expectation from this study was to find a higher renal papillary density caused by ipsilateral stone disease. The reason behind the incompatibility of the results of our study and previous published literatures may be explained by the fact that subjects in the other studies had not been selected among the patients with single side ureteral stone. Most studies have been performed in patients with kidney stones, not ureteral stones. The increased density of renal papillae in both sides, with or without renal stone, might be related to the presence of underlying metabolic abnormalities. Indeed, Shavit et al. found significant differences related to renal papillary density between kidney stone formers and healthy controls, whereas they were not found any association between higher papillary density and the level of hypercalciuria [23].

As known, in the case of urinary obstruction, there are five types of backflow; defined as pyelotubular, pyelosinus, pyelointerstitial, pyelolymphatic and pyelovenous [24-26]. Our results are most probably due to increased edema arising from partial/complete obstructive effect of the ureteral stone and the decrease in papillary densities caused by reverse backflow. One or more backflow types could be the cause of the decrease in the renal papillary density.

Based on these results, it can be speculated that, ipsilateral lower renal papillary density can be used to identify the side of the ureteral stone in cases where it is difficult to distinguish it from phleboliths and other artifacts, especially in patients without apparent ureterohydronephrosis.

The present study has some limitations. First, the number of included patients was relatively small: a larger number of patients would allow more significant statistical analysis, which might establish an absolute attenuation cutoff value. Second, the prevalence of mean papillary density in the general population or at least in the CT-explored population is unknown. A clinical study to determine a precise attenuation cutoff point that correlates with the clinical evaluation of calculi is needed in order to identify a population at high risk of developing stone disease.

In conclusion, $\mathrm{uCT}$ examination, which is used increasing frequency in urogenital radiology practice to identify of ureteral stone, allows for the determination of papillary density. During routine practical uCT applications, if phleboliths preclude the distinguishing of the side of ureteral 
stone or the existence of non-opaque ureteral stone, measurement of renal papillary density can be a practical method to identify the existence of ureter stone and its side.

\section{References}

1. Dalrymple NC, Verga M, Anderson KR, Bove P, Covey AM, Rosenfield AT, Smith RC. The value of unenhanced helical computerized tomography in the management of acute flank pain. J Urol. 1998; 159(3):735-40. [PMID: 9474137].

2. Türk C, Petř́ik A, Sarica K, Seitz C, Skolarikos A, Straub M, Knoll T. EAU Guidelines on Diagnosis and Conservative Management of Urolithiasis. Eur Urol. 2016; 69(3): 468-74. [PMID: 26318710].

3. Smith RC, Verga M, McCarthy S, Rosenfield AT. Diagnosis of acute flank pain: value of unenhanced helical CT. AJR Am J Roentgenol. 1996; 166(1): 97-101. [PMID: 8571915].

4. Randall A. Papillary pathology as a precursor of primary renal calculus. J Urol 1940; 44: 580-89.

5. Low RK, Stoller ML. Endoscopic mapping of renal papillae for Randall's plaques in patients with urinary stone disease. J Urol. 1997; 158(6): 2062-4. [PMID: 9366312].

6. Evan, A, Lingeman, J, Coe FL, Worcester E. Randall's plaque: pathogenesis and role in calcium oxalate nephrolithiasis. Kidney Int. 2006; 69(8): 1313-8. [PMID: 16614720].

7. Miller NL, Gillen DL, Williams JC, Evan AP, Bledsoe SB, Coe FL, Worcester EM, Matlaga BR, Munch LC, Lingeman JE. A formal test of the hypothesis that idiopathic calcium oxalate stones grow on Randall's plaque. BJU Int. 2009; 103(7): 966-71. [PMID: 19021625].

8. Kim SC, Coe FL, Tinmouth WW, Kuo, RL, Paterson RF, Parks $\mathrm{JH}$, Munch LC, Evan AP, Lingeman JE. Stone formation is proportional to papillary surface coverage by Randall's plaque. J Urol. 2005; 173(1): 117-9. [PMID: 15592050].

9. Miller NL, Williams JC Jr, Evan AP, Bledsoe SB, Coe FL, Worcester EM, Munch LC, Handa SE, Lingeman JE. In idiopathic calcium oxalate stone-formers, unattached stones show evidence of having originated as attached stones on Randall's plaque. BJU Int. 2010; 105(2): 242-5. [PMID: 19549258].

10. Evan AP, Lingeman JE, Coe FL, Parks JH, Bledsoe SB, Shao Y, Sommer AJ, Paterson RF, Kuo RL, Grynpas M. Randall's plaque of patients with nephrolithiasis begins in basement membranes of thin loops of Henle. J Clin Invest. 2003; 111(5): 607-16. [PMID: 12618515].

11. Matlaga BR, Coe FL, Evan AP, Lingeman JE. The role of Randall's plaques in the pathogenesis of calcium stones. J Urol. 2007; 177(1): 31-8. [PMID: 17161996].

12. Williams JC Jr, Matlaga BR, Kim SC, Jackson ME, Sommer AJ, McAteer JA, Lingeman JE, Evan AP. Calcium oxalate calculi found attached to the renal papilla: Preliminary evidence for early mechanisms in stone formation. J Endourol. 2006; 20(11): 885-90. [PMID: 17144856].

13. Ciudin A, Luque MP, Salvador R, Diaconu MG, Franco A, Collado-Belvis A, Sanchez J, Constantin V, Alvarez-Vijande R, Nicolau C, Alcaraz A. The evolution of CT diagnosed papillae tip microcalcifications: can we predict the development of stones? J Endourol. 2014; 28(8): 1016-21. [PMID: 24735416].

14. Eisner BH, Iqbal A, Namasivayam $S$, Catalano O, Kambadakone A, Dretler SP, Sahani DV. Differences in computed tomography density of the renal papillae of stone formers and non-stone-formers: a pilot study. J Endourol. 2008; 22(10): 2207-10. [PMID: 18831676].

15. Bhuskute NM, Yap WW, Wah TM. A retrospective evaluation of Randall's plaque theory of nephrolithiasis with CT attenuation values. Eur J Radiol. 2009; 72(3): 470-2. [PMID: 18947952].

16. Ciudin A, Luque Galvez MP, Salvador Izquierdo R, Franco de Castro A, Garcia-Cruz E, Alcover García J, Alvarez-Vijande García JR, Nicolau C, Alcaraz Asensio A. Unenhanced CT findings can predict the development of urinary calculi in stone-free patients. Eur Radiol. 2012; 22(9): 2050-6. [PMID 22572987].

17. Mostafavi MR, Ernst RD, Saltzman B. Accurate determination of chemical composition of urinary calculi by spiral computerized tomography. J Urol. 1998; 159(3): 673-5. [PMID: 9474123].

18. Garant M, Bonaldi VM, Taourel P, Pinsky MF, Bret PM. Enhancement patterns of renal masses during multiphase helical CT acquisitions. Abdom Imaging. 1998; 23(4): 431-6. [PMID: 9663282]

19. Dixon AK, Ashford NS, Sherwood T. Dense renal papillae: a quantitative study using computed tomography. Nephron. 1988; 49(4): 328-30. [PMID: 3412547].

20. Tublin ME, Tessler FN, McCauley TR, Kesack CD. Effect of hydration status on renal medulla attenuation on unenhanced CT scans. AJR Am J Roentgenol. 1997; 168(1): 257-9. [PMID: 8976956].

21. Starinsky R, Barr J, Lushkov G, Segal M, Manor A, Golik A. CT of renal densities caused by intravenous infusion of antibiotics. J Comput Assist Tomogr. 1995; 19(2): 228-31. [PMID: 7890847].

22. Ascenti G, Mazziotti S, Mileto A, Racchiusa S, Donato R, Settineri N, Gaeta M. Dual-source dual-energy CT evaluation of complex cystic renal masses. AJR Am J Roentgenol. 2012; 199(5): 1026-34. [PMID: 23096175].

23. Shavit L, Girfoglio D, Kirkham A, Allen D, Ferraro PM, Moochhala S, Unwin R. Increased renal papillary density in kidney stone formers detectable by CT scan is a potential marker of stone risk, but is unrelated to underlying hypercalciuria. Urolithiasis. 2016 Mar 29. [Epub ahead of print]

24. Bauer D. Pyelorenal backflow. Am J Roentgenol Radium Ther Nucl Med. 1957; 78(2): 296-316. [PMID: 13444525]. 
25. Olsson O. Backflow. Encyclopedia of Urology. Volume 5. Springer-Verlag, Berlin 1962; pp: 266-269.

26. Sengpiel GW. Renal backflow in excretory urography. Am J

Roentgenol Radium Ther Nucl Med. 1957; 78(2): 289-95.

[PMID: 13444524]. 